\title{
Epidemiology of Infective Endocarditis in Rural Upstate New York, 2011 - 2016
}

\author{
Saeeda Fatima ${ }^{\mathrm{a}, \mathrm{e}}$, Benajmin Dao ${ }^{\mathrm{a}}$, Ayesha Jameel ${ }^{\mathrm{a}}$, Konika Sharma ${ }^{\mathrm{a}}$, David Strogatz ${ }^{\mathrm{b}}$, \\ Melissa Scribani ${ }^{\mathrm{b}}$, Harish Raj Seetha Rammohan ${ }^{\mathrm{c}, \mathrm{d}}$
}

\begin{abstract}
Background: The epidemiology of infective endocarditis (IE) depends on a number of host factors whose prevalence can vary globally. The usual patient population affected by IE is sicker and older, often with many comorbid conditions. The risk is growing in younger populations due to the emerging epidemic of intravenous (IV) drug use. We have performed a temporal trend analysis of various factors of IE in the rural counties covering a major part of central Upstate New York.
\end{abstract}

Methods: We performed a retrospective analysis of electronic medical records of patients who were admitted in a tertiary care hospital in rural Upstate New York and diagnosed with IE from January 1, 2011 to December 31, 2016. Forty-five patients were identified with definite IE and nine with possible IE.

Results: Total incidence of IE was 3.5 cases per 100,000 person years in the total population and 4.4 if we consider total population $\geq 18$ years in the denominator. A significant $(P=0.022)$ increase in incidence of IE from 2011 to 2016 was seen by univariate analysis. Incidence was higher in males $(\mathrm{P}=0.029)$ and for those aged 65 or older $(\mathrm{P}=0.0003)$. IV drug use among cases is noted to be more prevalent in 2015 and 2016 compared to previous years.

Conclusion: In this study of patients in a rural region of New York, an increase in the incidence of IE was seen over the study period with changes in patient characteristics and etiology over this time. We speculate that an increase in IV drug use could be a leading factor in the recent and future increased incidence of IE in the area.

Keywords: Infective endocarditis; Epidemiology; Intravenous drug

Manuscript submitted July 11, 2017, accepted July 21, 2017

aDepartment of Medicine, Bassett Medical Center, 1 Atwell Road, Cooperstown, NY 13326, USA

${ }^{b}$ Research Institute, Bassett Medical Center, 1 Atwell Road, Cooperstown, NY 13326, USA

'Department of Cardiology, Bassett Medical Center, 1 Atwell Road, Cooperstown, NY 13326, USA

${ }^{\mathrm{d} C}$ Columbia University of Physicians \& Surgeons, NY 10032, USA

${ }^{\mathrm{e} C}$ Corresponding Author: Saeeda Fatima, Department of Medicine, Bassett

Medical Center, 1 Atwell Road, Cooperstown, NY 13326, USA.

Email: saeeda.fatima@bassett.org

doi: https://doi.org/10.14740/jocmr3131w use

\section{Introduction}

The epidemiology of infective endocarditis (IE) depends on a number of host factors whose prevalence can vary globally. Yearly incidence is about $3-10$ per 100,000 people [1]. Several factors have impacted the clinical spectrum of IE including decreased incidence of rheumatic carditis, increased use of intra-cardiac devices, emerging population of high-risk patients (including hemodialysis, intravenous (IV) drug users, and diabetes) as well as improved diagnostic tools and management of IE [2]. The usual patient population affected by IE is sicker and older, often with many comorbid conditions. The risk is growing in younger populations due to the emerging epidemic of IV drug use. We have performed a temporal trend analysis of various factors of IE in the rural counties covering a major part of central Upstate New York.

\section{Materials and Methods}

We performed a retrospective analysis of electronic medical records of patients who were admitted in a tertiary care hospital in rural Upstate New York and diagnosed with IE from January 1, 2011 to December 31, 2016. Five counties of Upstate New York are covered by this tertiary care center: Otsego, Herkimer, Delaware, Chenango and Schoharie Counties. All patients over 18 years of age admitted with diagnosis of IE (ICD-10 codes 133.0) were included in the study. A total of 54 patients were identified and admitted during this time period. For each of these cases, the medical records were thoroughly reviewed to verify possible and definite IE according to the modified Duke's criteria [3]. Forty-five patients were identified with definite IE and nine with possible IE.

Demographic, clinical, laboratory and outcome data were collected using a standardized data collection form with detailed definition of variables. Death information at 6 months was obtained from the electronic medical record. The definitions of community-acquired, nosocomial, and health care-associated infections were described by Correa de Sa et al [4] and we followed the same definitions. This study was approved by 


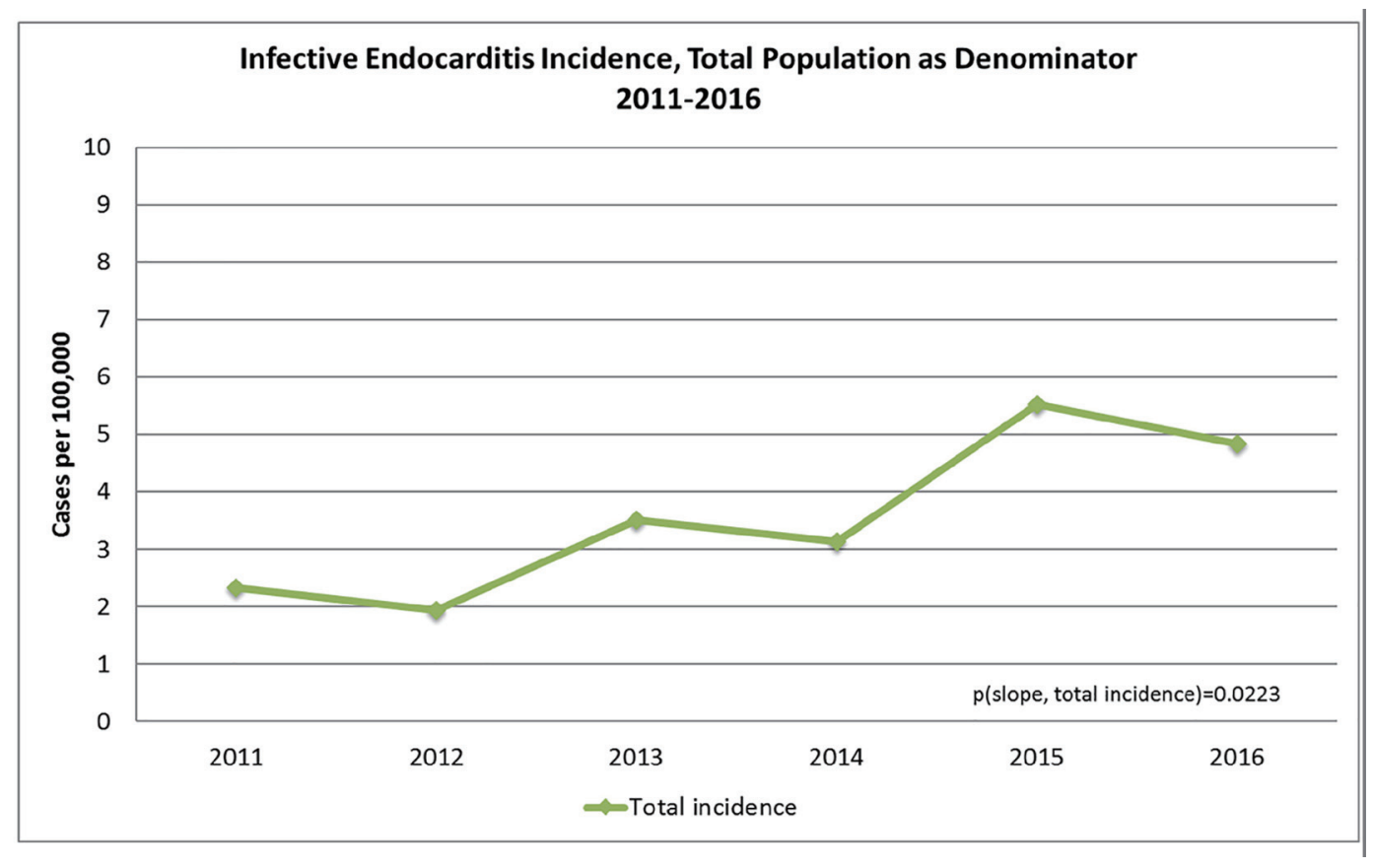

Figure 1. Total incidence of IE from 2011 to 2016.

the Bassett Institutional Review Board.

Statistical analyses included linear regression and the ztest for comparing incidence rates. For estimating incidence rates, the total population of the above mentioned counties between the years 2011 and 2016 was considered to be at risk, with counts of age-, sex-, and calendar time-specific strata in the denominator enumerated from the collective annual census data of the 6 years $(2011-2016)$. All analyses were performed using the statistical programming language SAS.

\section{Results}

Total incidence of IE was 3.5 cases per 100,000 person years (Fig. 1) in the total population and 4.4 if we consider total population $\geq 18$ years in the denominator. From

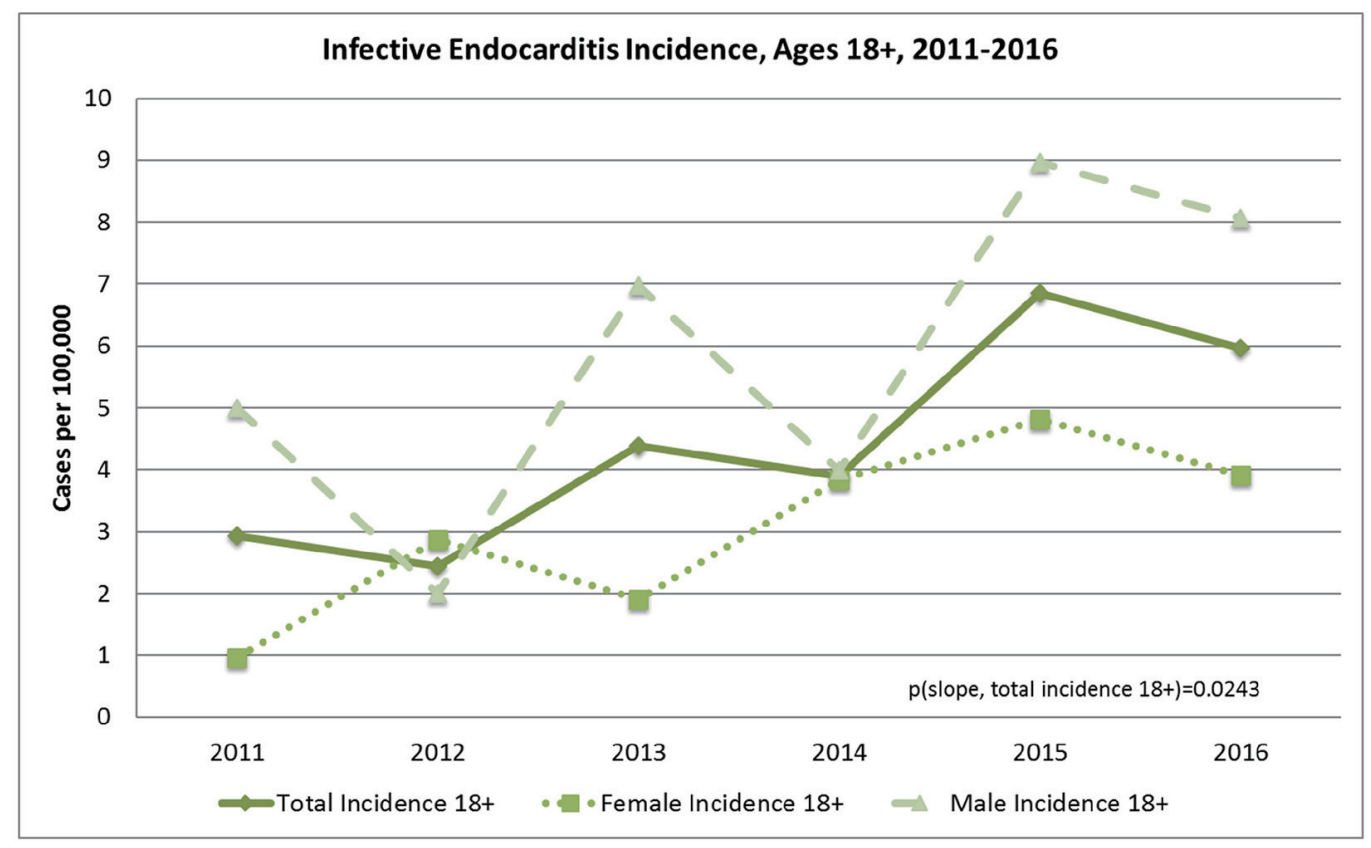

Figure 2. Incidence of IE in population 18 years and older from 2011 to 2016. 


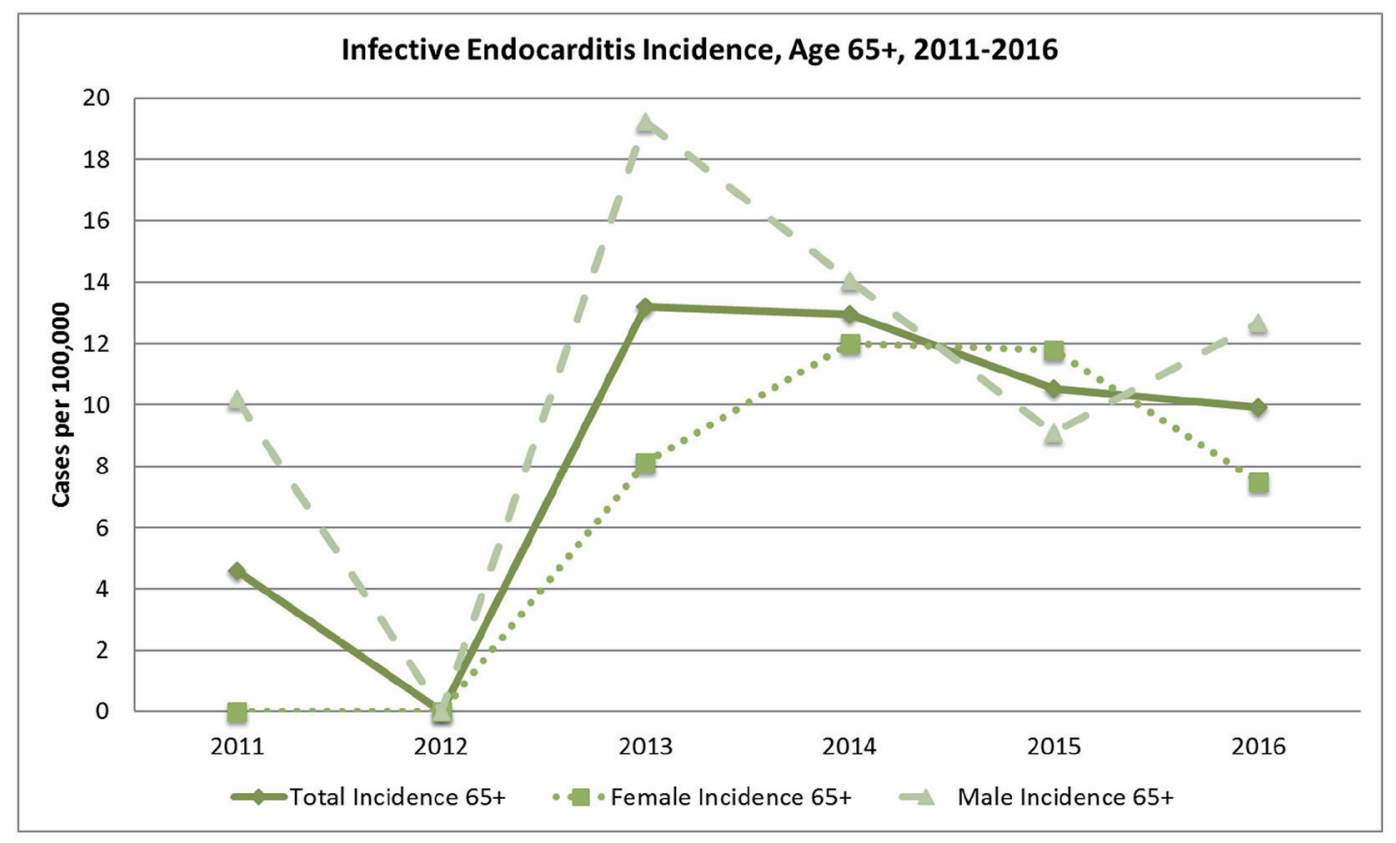

Figure 3. Incidence of IE in population 65 years and older from 2011 to 2016.

a univariate analysis there was significant $(P=0.022)$ increase in incidence of IE from 2011 to 2016. Using the ztest for comparing incidence rates, incidence was higher in males $(\mathrm{P}=0.029)$ and for those aged 65 or older $(\mathrm{P}=$ 0.0003 ) (Figs. 2 and 3). IV drug use among cases is noted to be more prevalent in 2015 and 2016 compared to previous years (Table 1). Other common predisposing conditions include previous IE $(22.2 \%)$, history of cardiac surgery $(29.6 \%)$ and implantable intra-cardiac device $(14.8 \%)$. There was just one case of rheumatic carditis and no cases of mitral valve prolapse.

Clinical characteristics are summarized in Table 2. Comorbidities associated with IE include diabetes 38.8\%, distant infections $22.2 \%$, pre-existing valvular heart disease $28.8 \%$, heart failure $20.4 \%$, atrial fibrillation $24.07 \%$ and renal insufficiency $24.1 \%$ with $12.9 \%$ dialysis-dependent population. Infection site of acquisition was predominantly communityacquired $(79.6 \%)$, with some additional healthcare-associated cases $(16.7 \%)$ and only two cases of nosocomial. Of the cases, $72.2 \%$ had native valve IE, with $48 \%$ having mitral valve involvement and $22.2 \%$ having aortic valve involvement. There were seven cases $(12.9 \%)$ with prosthetic valve-associated IE. Although involvement of the pulmonary valve is rarely seen, several cases were identified in this small cohort $(5.5 \%$; $n=$ 3).

Microbiology and clinical outcomes are also summarized in Table 2. Of the 54 cases, $21(38.3 \%)$ were due to Staphylococcus aureus, nine $(16.6 \%)$ were streptococci, nine $(16.6 \%)$ from enterococcus species, six (11\%) were coagulase negative, six $(11 \%)$ were culture negative and none were due to the HACEK (Hemophilus species, Aggregatibacter species, Cardiobacterium hominis, Eikenella corrodens, and Kingella species) group. Among the staphylococcus, seven cases were methicillin-resistant. Of the 54 cases of IE, 18 patients $(33.3 \%)$ had indication for surgery. Fifteen $(27.7 \%)$ patients needed surgery within 6 weeks, but only eight patients underwent surgery in the first 6-week period. Other patients had surgery after 6 weeks' period. Patients who did not have surgery $(n=6)$ were either deemed too high risk or refused the procedure. In-hospital death rate was 5.5\% and 6-month mortality was $9.2 \%$. Median length of stay was calculated 11 days.

Table 1. Incidence of IE From 2011 to 2016 in IV Drug Users

\begin{tabular}{|llll}
\hline Year of admission & $\begin{array}{l}\text { Number of cases } \\
\text { diagnosed with IE }\end{array}$ & $\begin{array}{l}\text { Number of cases } \\
\text { with reported IV drug use }\end{array}$ & $\begin{array}{l}\text { Percentage (\%) of cases } \\
\text { using IV drugs }\end{array}$ \\
\hline 2011 & 6 & 1 & 16.7 \\
2012 & 5 & 1 & 20 \\
\hline 2013 & 9 & 1 & 11.1 \\
\hline 2014 & 8 & 0 & 0 \\
\hline 2015 & 14 & 6 & 42.9 \\
\hline 2016 & 12 & 4 & 33.3 \\
\hline
\end{tabular}


Table 2. Characteristics of Patients

\begin{tabular}{|c|c|}
\hline Variables & IE, $2011-2016, n=54$ \\
\hline \multicolumn{2}{|l|}{ Demographics } \\
\hline Age, median years (range) & $61.5(21-93)$ \\
\hline Female gender & $19(35 \%)$ \\
\hline Race (Caucasian) & $54(100 \%)$ \\
\hline \multicolumn{2}{|l|}{ Diagnosis } \\
\hline Definite IE & $45(85 \%)$ \\
\hline Possible IE & $9(14 \%)$ \\
\hline \multicolumn{2}{|l|}{ Comorbidities } \\
\hline Diabetes mellitus & $21(38.8 \%)$ \\
\hline HIV & $1(1.85 \%)$ \\
\hline Neoplasm & $6(11.1 \%)$ \\
\hline Other immunosuppressed states & $2(3.7 \%)$ \\
\hline Valvular heart disease & $15(28.8 \%)$ \\
\hline Heart failure & $11(20.4 \%)$ \\
\hline Bicuspid aortic valve & $1(1.85 \%)$ \\
\hline Atrial fibrillation & $13(24.07 \%)$ \\
\hline Distant infections & $12(22.2 \%)$ \\
\hline Pulmonary disease & $11(20.37 \%)$ \\
\hline Renal insufficiency & $13(24.1 \%)$ \\
\hline Dialysis dependent & $7(12.9 \%)$ \\
\hline \multicolumn{2}{|l|}{ Predisposing factor } \\
\hline Rheumatic heart disease & $1(1.85 \%)$ \\
\hline Mitral valve prolapse & 0 \\
\hline IV drug use & $13(24.1 \%)$ \\
\hline Previous cardiac surgery & $16(29.6 \%)$ \\
\hline Congenital heart disease & $1(2.38 \%)$ \\
\hline Previous IE & $12(22.2 \%)$ \\
\hline Implantable intra-cardiac device & $8(14.8 \%)$ \\
\hline Central venous line & $6(11.1 \%)$ \\
\hline \multicolumn{2}{|l|}{ Affected valve } \\
\hline Native valve & $39(72.2 \%)$ \\
\hline Prosthetic valve & $7(12.9 \%)$ \\
\hline Lead infection & $8(14.8 \%)$ \\
\hline Aortic & $12(22.2 \%)$ \\
\hline Mitral & $26(48 \%)$ \\
\hline Tricuspid & $7(12.9 \%)$ \\
\hline Pulmonary & $3(5.5 \%)$ \\
\hline \multicolumn{2}{|l|}{ Site of acquisition } \\
\hline Community acquired & $43(79.6 \%)$ \\
\hline Nosocomial & $2(3.7 \%)$ \\
\hline Healthcare associated & $9(16.7 \%)$ \\
\hline \multicolumn{2}{|l|}{ Causative organism } \\
\hline S. aureus & $21(38.3 \%)$ \\
\hline MSSA & $14(66.6 \%)$ \\
\hline MRSA & $7(33.3 \%)$ \\
\hline Coagulase negative Staph & $6(11 \%)$ \\
\hline Streptococcus species & $9(16.6 \%)$ \\
\hline Enterococcus & $9(16.6 \%)$ \\
\hline Culture negative & $6(11 \%)$ \\
\hline Others & $3(5.5 \%)$ \\
\hline \multicolumn{2}{|l|}{ Outcomes } \\
\hline Median length of stay & 11 \\
\hline In-hospital death & $3(5.5 \%)$ \\
\hline 6-month mortality & $5(9.2 \%)$ \\
\hline Valve surgery indicated (within 6 weeks) & $15(27.7 \%)$ \\
\hline Valve surgery indicated ( 6 week to 1 year) & $3(5.5 \%)$ \\
\hline Valve surgery performed (within 6 weeks) & $8(14.8 \%)$ \\
\hline Valve surgery performed ( 6 week to 1 year) & $4(7.4 \%)$ \\
\hline
\end{tabular}

\section{Discussion}

Understanding the epidemiologic trends of IE is important in its prevention, diagnosis and treatment. Our study period is after changes in the prevention of IE guidelines that were revised in 2007 , so our time trends are not likely to be affected by this transition. The overall incidence of IE in the area appeared to be similar to that of the United States [5, 6]. A significant increase in IE was observed within the community during the study period. An increase in IV drug use among cases is also observed in the last 2 years of study period, which reflects an important behavioral pattern in this and other rural communities [7-9]. Staphylococcus aureus has become the predominant causative organism in the developed world. This can be attributed to the increase in risk factors in the population including older age, diabetes, end-stage renal disease, intra-cardiac device, increased use of invasive procedures and IV drug use [10]. It remained the predominant pathogen in communityacquired and healthcare-related endocarditis and can lead to an aggressive form of disease [11]. There is a general decreasing trend in nosocomial endocarditis in the United States and similar results are seen in our study. This decrease coincided with coordinated efforts to reduce hospital-acquired infections through evidence-based consensus guidelines, bundled interventions, and public reporting $[12,13]$. We observed a lower proportion of patients undergoing surgery, in-hospital and 6-month mortality as compared to other studies $[1,5]$.

Our study has several limitations. Although the tertiary care hospital in this study is the major hospital located within the five county rural regions, referral bias is possible if some IE patients were admitted to hospitals in other nearby counties $[14,15]$. There are no standard codes to identify skilled home nursing care and wound care, which are normally included in the definition of health care-associated infection; consequently, the number of health care-associated infections could have been underestimated. The population is predominantly Caucasian, rural middle to low socioeconomic class which may make our study less generalizable to more urban and racially diverse populations. Information regarding death was acquired from the electronic medical record and was not confirmed by the state health department. This may have resulted in underestimation of mortality.

\section{Conclusion}

In this study of patients in a rural region of New York, an increase in the incidence of IE was seen over the study period with changes in patient characteristics and etiology over this time. In general, male gender and older age were associated with increased IE risk. We speculate that an increase in IV drug use could be a leading factor in the recent and future increased incidence of IE in the area.

\section{Acknowledgments}

We acknowledge Bassett Research Institute. 


\section{Competing Interests}

The authors declare that they have no competing interests.

\section{Grant Support}

None.

\section{References}

1. Cahill TJ, Prendergast BD. Infective endocarditis. Lancet. 2016;387(10021):882-893.

2. Slipczuk L, Codolosa JN, Davila CD, Romero-Corral A, Yun J, Pressman GS, Figueredo VM. Infective endocarditis epidemiology over five decades: a systematic review. PLoS One. 2013;8(12):e82665.

3. Li JS, Sexton DJ, Mick N, Nettles R, Fowler VG Jr, Ryan T, Bashore T, et al. Proposed modifications to the Duke criteria for the diagnosis of infective endocarditis. Clin Infect Dis. 2000;30(4):633-638.

4. Correa de Sa DD, Tleyjeh IM, Anavekar NS, Schultz JC, Thomas JM, Lahr BD, Bachuwar A, et al. Epidemiological trends of infective endocarditis: a population-based study in Olmsted County, Minnesota. Mayo Clin Proc. 2010;85(5):422-426.

5. DeSimone DC, Tleyjeh IM, Correa de Sa DD, Anavekar NS, Lahr BD, Sohail MR, Steckelberg JM, et al. Temporal trends in infective endocarditis epidemiology from 2007 to 2013 in Olmsted County, MN. Am Heart J. 2015;170(4):830-836.

6. Pant S, Patel NJ, Deshmukh A, Golwala H, Patel N, Badheka A, Hirsch GA, et al. Trends in infective endocarditis incidence, microbiology, and valve replacement in the United States from 2000 to 2011. J Am Coll Cardiol. 2015;65(19):2070-2076.

7. Substance abuse in rural areas introduction - rural health information hub [Internet]. [cited 2017 Jul 7]. Available from: https://www.ruralhealthinfo.org/topics/substanceabuse.

8. Park H, Bloch M. How the epidemic of drug overdose deaths ripples across America. The New York Times [Internet]. 2016 Jan 7 [cited 2017 Jul 7]; Available from: https://www.nytimes.com/interactive/2016/01/07/us/ drug-overdose-deaths-in-the-us.html.

9. Heroin_and_opioids.pdf [Internet]. [cited 2017 Jul 7]. Available from: https://www.osc.state.ny.us/press/releases/june16/heroin_and_opioids.pdf.

10. Noskin GA, Rubin RJ, Schentag JJ, Kluytmans J, Hedblom EC, Smulders M, Lapetina E, et al. The burden of Staphylococcus aureus infections on hospitals in the United States: an analysis of the 2000 and $2001 \mathrm{Na}-$ tionwide Inpatient Sample Database. Arch Intern Med. 2005;165(15):1756-1761.

11. Benito N, Miro JM, de Lazzari E, Cabell $\mathrm{CH}$, del Rio A, Altclas J, Commerford P, et al. Health care-associated native valve endocarditis: importance of non-nosocomial acquisition. Ann Intern Med. 2009;150(9):586-594.

12. Berwick DM, Calkins DR, McCannon CJ, Hackbarth AD. The 100,000 lives campaign: setting a goal and a deadline for improving health care quality. JAMA. 2006;295(3):324-327.

13. Marsteller JA, Hsu YJ, Weeks K. Evaluating the impact of mandatory public reporting on participation and performance in a program to reduce central line-associated bloodstream infections: evidence from a national patient safety collaborative. Am J Infect Control. 2014;42(10 Suppl):S209-215.

14. Al-Hasan MN, Eckel-Passow JE, Baddour LM. Influence of referral bias on the clinical characteristics of patients with Gram-negative bloodstream infection. Epidemiol Infect. 2011;139(11):1750-1756.

15. Kokmen E, Ozsarfati Y, Beard CM, O'Brien PC, Rocca WA. Impact of referral bias on clinical and epidemiological studies of Alzheimer's disease. J Clin Epidemiol. 1996;49(1):79-83. 